\title{
Politique
}

Politique

\section{Réponse à un ami canadien. Précédé de lettres à un ami québécois de Philip RESNICK et Daniel LATOUCHE, Montréal, Boréal, 1990, 174 p.}

\section{Josée Legault}

Numéro 19, hiver 1991

URI : https://id.erudit.org/iderudit/040694ar

DOI : https://doi.org/10.7202/040694ar

Aller au sommaire du numéro

Éditeur(s)

Société québécoise de science politique

ISSN

0711-608X (imprimé)

1918-6584 (numérique)

Découvrir la revue

Citer ce compte rendu

Legault, J. (1991). Compte rendu de [Réponse à un ami canadien. Précédé de lettres à un ami québécois de Philip RESNICK et Daniel LATOUCHE, Montréal, Boréal, 1990, 174 p.] Politique, (19), 149-153. https://doi.org/10.7202/040694ar

Ce document est protégé par la loi sur le droit d'auteur. L'utilisation des services d’Érudit (y compris la reproduction) est assujettie à sa politique d'utilisation que vous pouvez consulter en ligne.

https://apropos.erudit.org/fr/usagers/politique-dutilisation/
Cet article est diffusé et préservé par Érudit.

Érudit est un consortium interuniversitaire sans but lucratif composé de l'Université de Montréal, l'Université Laval et l'Université du Québec à Montréal. Il a pour mission la promotion et la valorisation de la recherche. https://www.erudit.org/fr/ 


\section{Réponse à un ami canadien.}

Précédé de lettres à un ami québécois

de Philip RESNICK et Daniel LATOUCHE, Montréal, Boréal, 1990, 174 p.

Née du traumatisme subi par la "gauche» libérale et néodémocrate canadienne-anglaise suite à l'appui du Québec au Traité de libre-échange et I'Accord du Lac Meech, cette traduction de "Letters to a Québécois friend", du politologue Philip Resnick, professeur à l'Université of British Columbia lesquelles dix lettres sont suivies d'une réponse musclée de son homologue Daniel Latouche - se veut une tentative de faire comprendre aux Québécois francophones l'état d'esprit dans lequel s'est retrouvé le Canada anglais au lendemain de l'échec de Meech.

Dans un premier temps, Resnick nous éclaire sur la façon dont a été reçu au Canada anglais cet appui du Québec au libre-échange et à Meech. Thème récurrent de ces lettres, cet appui a été vu comme une double trahison ayant résulté, du moins selon Resnick, en une confiscation délibérée de l'identité canadienne (p. 77). Pour appuyer ses dires, l'auteur soutient que le Québec a constamment rejeté le concept même d'identité canadienne-anglaise, laquelle s'est peu à peu fondée sur une «identification profonde aux institutions de l'État fédéral» (p. 34).

Accusant ensuite le Québec français d'un second rejet, soit celui de sa minorité anglophone, Resnick procède à une critique acerbe des Lois 101 et 178 et reprend la thèse du Commissaire aux langues officielles, D'lberville Fortier, sur I' «humiliation» des Québécois anglophones (pp. 35-42). L'auteur conclut que ces lois sont le fruit d'une attitude revancharde et mesquine de la part des Franco-Québécois (p. 40).

Resnick tente ensuite une analyse comparative des nationalismes franco-québécois et anglo-canadien. Reprenant l'argument trudeauiste voulant que seule la «bourgeoisie" francophone ait profité des effets bénéfiques de la Révolution tranquille, l'auteur laisse ensuite sous-entendre que le nationa- 
lisme canadien-anglais serait d'une forme "supérieure», puisqu'il ne recèle pas ces éléments "linguistiques" et «défensifs" qui caractériseraient celui du Québec. Resnick ira jusqu'à expliquer, en partie, l'échec de ce pays par cette "obsession d'imposer l'hégémonie de la langue et de la culture française à tout le Québec» (p. 72).

Afin de sauver le Canada, Resnick termine en proposant un vague projet d'inspiration post-moderne, lequel irait dans le sens d'un plus grand respect de l'altérité et de la différence; respect qui aurait été jusqu'ici démontré beaucoup plus par le Canada anglais que par le Québec (p. 98). II faudra alors que ce dernier s'ouvre et apprenne à mieux connaître le reste du pays, ce que les Canadiens anglais auraient déjà fait. Proposant à la toute fin de faire $f i$ de nos luttes nationales et linguistiques, Resnick suggère de nous unir et de monter aux barricades afin de combattre le véritable ennemi commun, soit le néo-conservatisme (p. 116).

Quoiqu'empruntant surtout la voie de la dérision, la réponse de Daniel Latouche Fini le zigonnage! Réponse impertinente d'un Québécois impoli, quant à elle, réussit tout de même à réfuter l'argumentation de Resnick. Au-delà de l'exaspération clairement exprimée par Latouche "d'abord, laisse-moi te dire qu'on vous aime, vous et vos montagnes Rocheuses" (p. 124); "tes convictions sont à ce point irrationnelles, que je désespère de pouvoir jamais les secouer" (p. 128), celui-ci refuse un discours de l'altérité qui prétend toutefois imposer à l'Autre ses propres règles de conduite (p. 134). Latouche réfute également les accusations d'intolérance que Resnick profère à l'endroit du Québec vis-à-vis sa minorité anglophone "cela me surprendrait que Westmount rêve de devenir un autre Saint-Boniface» (p. 158). Renvoyant ainsi l'ascenseur, Latouche ne se laisse pas émouvoir par des Canadiens anglais qui, selon lui, ont tout fait ou presque afin d'assimiler leurs compatriotes francophones. Sur cette note, Latouche termine en tentant d'expliquer à son collegue le caractère progressiste du nationalisme québécois des 30 dernières années, lequel $n$ 'aura pas, contrairement à ce que véhicule le mythe d'origine trudeauiste, favorisé qu'une 
poignée de "bourgeois" en attente d'un nouveau statut national.

Par contre, se voulant un ouvrage sérieux de science politique, les lettres de Philip Resnick frisent parfois la science-fiction. Ainsi, placée sous la lorgnette d'un penseur prêt à se départir d'une certaine rigueur intellectuelle afin de mieux laisser couler son trop-plein d'émotivité, l'affirmation nationale des Franco-Québécois des trois dernières décennies se trouve réduite à un débordement d'égoïsme et d'ethnocentrisme excessifs ayant causé l'échec de ce beau et grand pays qu'est le Canada. C'est ainsi que, selon Resnick, le Québec ne serait même pas digne de l'héritage du Siècle des lumières (p. 42). Victimisant par le fait même ses compatriotes anglosaxons, dont la bonne volonté aurait été répudiée par un Québec assoiffé de pouvoir, l'auteur classe en fait le Québec parmi les capitales mondiales de l'égoïsme et de l'ethnocentrisme.

De plus, dans ces lettres par trop émotives, certaines confusions conceptuelles plutôt étonnantes sont à signaler. Par exemple, l'auteur met sur le même pied le droit à l'enseignement dans sa langue et les "droits humains les plus fondamentaux" (p. 19). Il oublie de ce fait que, contrairement à certaines législations linguistiques promulguées depuis la Confédération par des législatures anglophones visant à assimiler les francophones minoritaires, la Loi 101 reconnaît pleinement à la minorité anglo-québécoise ce droit réel, puisqu'un réseau scolaire complet de langue anglaise existe au Québec.

Une autre confusion à signaler concerne la nature même du "phénomène" franco-québécois. Tantôt "société libre et égale" au Canada anglais (p. 16), tantôt "collectivité sociologique distincte" (p. 21), tantôt "minorité» (p. 54), tantôt "élément primordial de la mosaïque canadienne" (p. 20), on a peine à bien saisir dans quelle niche socio-politique l'auteur loge les Franco-Québécois. Pas étonnant alors que, ne sachant pas très bien à qui il adresse ses lettres, il préfère se livrer à une thérapie dont le seul but semble être celui de se défouler face à ce Québec francophone qui a osé trahir l'idéal socialiste (p. 49). Car voilà, aux yeux de la gauche cana- 
dienne-anglaise et de Resnick lui-même, le véritable péché commis par le Québec, a été son incapacité à faire la révolution socialiste. On peut ainsi lire en filigrane que le Québec, en ayant développé sa propre bourgeoisie, a commis l'erreur historique de passer d'une minorité sympathique, parce que écrasée, à une majorité menaçante. C'est d'ailleurs la raison pour laquelle cette intelligentsia d'outre-Outaouais a maintenant jeté son dévolu sur de nouvelles causes, beaucoup plus méritoires à ses yeux, parce que tenant un discours d'opprimés clair et net, soit celles des Autochtones et des Anglo-Québécois (pp. 35-42). Que cette gauche bienpensante $n$ 'ait jamais accordé la moindre attention au sort que subissent les francophones hors Québec depuis plus d'un siècle en dit long sur le sérieux de l'analyse de celle-ci.

Par contre, il ne faudrait pas sous-estimner la frustration qui grandit au Canada anglais, et que Resnick semble ressentir fortement, face à un Québec qui ne cesse de vouloir réformer le Canada à son image plutôt que de se doter de son propre État. René Lévesque ne le prédisait-il pas déjà, en 1967, dans son ouvrage Option Québec :

II est clair, quant à nous, que cette frustration risque de devenir intolérable. Et c'est justement dans les groupes les plus progressistes et nationalistes du Canada anglais, où l'on se préoccupe de l'invasion économique, culturelle et politique des États-Unis et des moyens d'empêcher le pays de s'y abandonner tout à fait, que risque de grandir à ce propos et d'éclater au grand jour un violent ressentiment à l'égard du Québec.

Cependant, force est de reconnaître que l'évolution récente de cette intelligentsia canadienne-anglaise, se remettant peu à peu du double traumatisme du libre-échange et de l'échec de Meech, démontre une certaine volonté d'aller audelà des nombreuses admonestations qui sont servies aux Québécois dans les lettres de Resnick. Ces dernières, écrites 
sous le coup d'une émotion peu propice à l'analyse et trempées dans l'encre de l'amertume, gagneraient donc à être remisées au plus vite dans un placard à pamphlets. Ces temps-ci, elles ne devraient pas se sentir trop seules...

Fort heureusement cependant, Philip Resnick a eu le temps de se remettre de ses émotions. N'ayant de toute évidence pas été tenté de récidiver, il vient tout juste de publier Toward A Canada-Québec Union, un ouvrage "sérieux" d'analyse, beaucoup plus intéressant et pertinent que ses lettres à un ami québécois.

Josée Legault

Université du Québec à Montréal 